\title{
اشتهاء الطيبات: ليس مجرد تذوق فحس!
}

\section{Beyond the appetite of good food: addiction!}

Prof. Dr. Samer J. Rudwan ". د سامر جميل رضوان

هل تعاني من نوبات شديدة من الإحساس بالثهية العارمة لتناول طعام معين أو قطعة حلوى؟ هل يصبح تركيزك أفضل إذا ما دخنت سيجارة، خصوصاً إذا كنت جالساً في مكتبك تقرأ أو تفكر بمسألة ما؟ وهل تشتمتع مساءً وأنت تجلس أمام التلفزبون، تقلبه من محطة لأخرى و تتناول المكسرات أو قطع الشوكولاته؟ وهل أنت ممن لا يستطيعون صباحاً البدء بأي نشاط قبل ارتناف فنجان من القهوة أو الثاي؟ وهل أنت من الأشخاص الذين "يمرضون" إذا لم يعملوا بدأب طوال النهار، ويجدون صعوبة في التوقف عن العمل أو إرجاء ما لم يتم إنجازه للغد.... إذا كنت واحداً من هؤلاء، وأجبت بنعم عن واحد أو أكثر من الأسئلة المطروحة أعلاه، فقد تقف على إحدى درجات السلم الذي تسمى نهايته الإدمان. إذ ليس بالضرورة أن يتعاطى الإنسان المخدرات بأنواعه المختلفة أو يشرب الكحول حتى تطلق عليه صفة المدمن. فلإدمان أنواع. حتى ما يسمى بـ "عقاقير" الحياة اليومية، كالتثخين والثاي والقهوة والثوكولاته و المكسرات و مشاهدة التلفزيون أو استعمال الحاسب، بإسراف إلخ تعد من الأشياء التي يمكن أن تسبب الإدمان عليها، والتعود إلى درجة أن أجسادنا لا تشعر بالراحة والهدوء إلا عند تتاول ما اعتدنا تتاوله أو ممارسة ما اعتدنا ممارسته باستمرار • وحتى التعلق بشخص آخر، والاعتقاد بأن الحياة ستصبح جحيماً من دونه يمكن اعتباره شكلاً من أشكال الإدمان (العاطفي). ويرى العلماء اليوم أن هذا التعود ليس مجرد اعتياد نفسي أو عادة اعتدنا ممارستها بصورة آلية إن جاز التعبير، وإنما يملك في كثير من جوانبه أساساً حيوياً يمكن فهمه وتفسيره، أي أنه يرتبط بإفراز مواد كيماوية محددة في الدماغ تحدد سلوكنا واتجاهاتتا نحو الأثياء والأشخاص.

الإنسان مخلوق إدماني بطبيعته، بمعنى أنه يتعود أو يعوّد نفسه خلال مجرى حياته على أثياء وأمور كثيرة إلى درجة أنه يصعب عليه في النهاية أن يتخلص منها أو يخفف مما اعتاد عليه. لقد خلق الله سبحانه وتعالى الدماغ الإنساني المعقد والغامض الذي يكتشف العلماء مزيداً من أسراره الكامنة يوماً بعد الآخر • ومن الخصائص المعروفة اليوم أن الدماغ الإنساني مبرمج وفق آلية توصيل معقدة تقوم في أساسها على "برنامج" يعمل وفق مبدأ

\footnotetext{
${ }^{*}$ Prof. Dr. Samer J. Rudwan, Department of Education \& Cultural Studies, College of Arts \& Sciences, University of Nizwa, Oman. Email: srudwan@hotmail.com
} 
تجنب الألم والإزعاج والبحث عن المتعة أو الراحة (أو التوازن). وعندما نتتاول مادة ذات طعم لذيذ أو نمارس

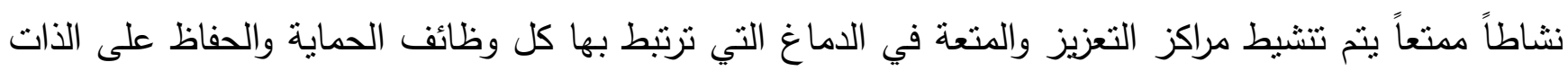
ووظائف الطعام والثراب إلخ.

يقول البروفيسور "ألان مارلات" مدير مركز أبحاث الإدمان في جامعة واثنطن مبرراً سبب إطلاق صفة

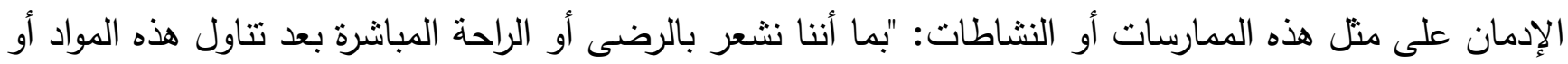

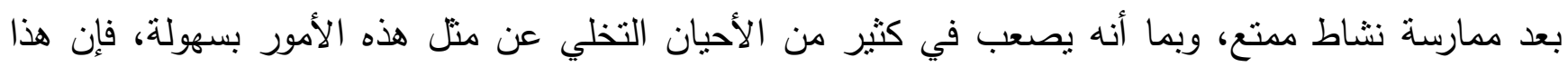

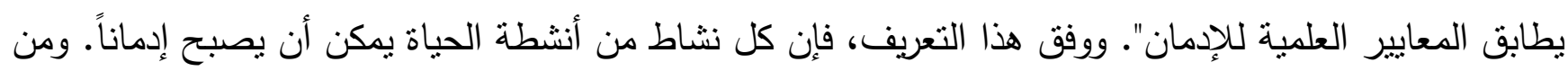

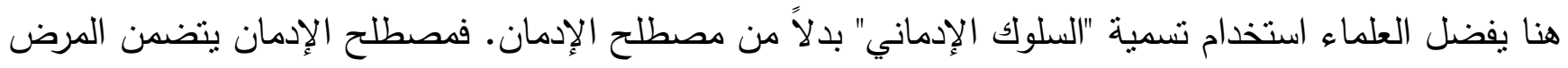

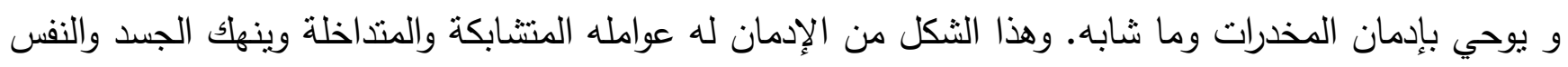
ويحطم الروابط الاجتماعية والأخلاقية والدينية. ولكن، كلما تمكن العلماء من فهم الآليات الحيوية والعصبية والنفسية للاماغ ، أمكن تحديد العلاقة الكامنة بين اللذة و الإدمان وتطوير وسائل أفضل للمساعدة عندما ينزلق المبدأ الطبيعي للذة في أسر الإدمان ويصبح عبداً لها.

ولكن، لماذا لم تحظ الحقيقة القائلة: "إن ملايين البشر يعانون من نوع من أنواع الإدمان على التدخين أو

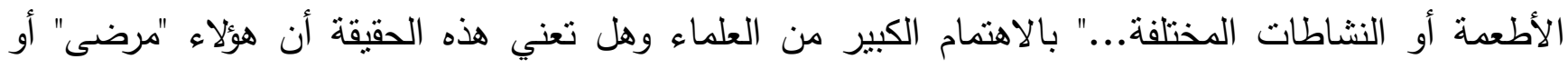

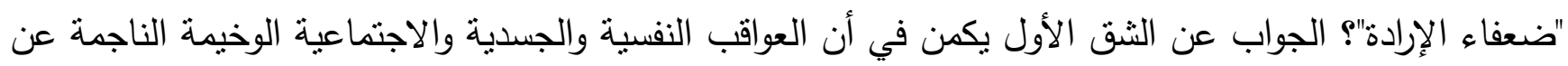
إدمان المخدرات، كالحشيش والهيروين والكوكائين وما يشبه ذلك، قد جعلت اهتمام العلماء والحكومات والمؤسسات الأخرى ينصب بصورة مكثفة على هذا النوع من الإدمان ومخاطره أكثر من الاهتمام بمسألة الاهنمام "بعادات سلوكية يومية أو بعقاقير الحياة اليومية". أما الإجابة عن الثق الثاني من السؤال حول الإرادة فهي بالنفي طبعاً.

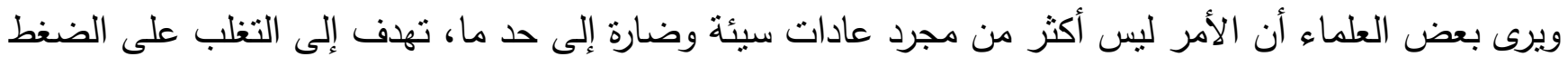

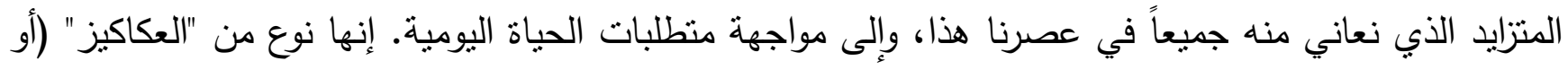

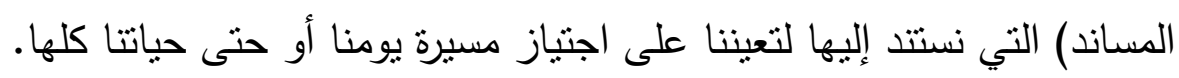

وسواء استهلك الإنسان "عقاقير الحياة اليومية" هذه بشكل واعٍ أم دون وعي، فإنها قد نساعد في تخفيف

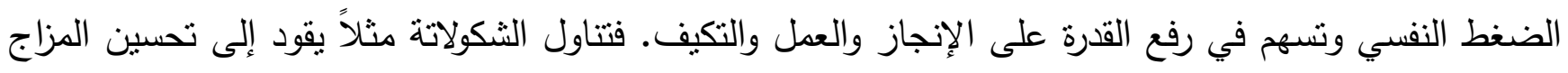
نوعاً ما. ومن يشعر بالغم والحزن والانحطاط يستطيع من خلال تتاولها أن يقدم لدماغه مادة منشطة سريعة التأثنر . 
ويرى العلماء أن خبرات اللذة (أو التعزيز) التي يقدمها الإنسان لنفسه كمكافأة ذاتية نقوم بتقوية جهاز المناعة لديه، وتعمل كموانع ضد الكثير من أنواع الضغط المحيطة بنا، كالضجيج والحرارة والمنافسة ووسائط النقل والعمل الإضافي إلخ.

\section{ما هي الوظيفة التي تؤديها "عقاقير الحياة اليومية" هذه؟}

وهل تتاولها بانتظام هو من العادات الصحية الخطيرة فعلاً أم أن هناك أساس حيوي لذلك؟ لنتاول بعض

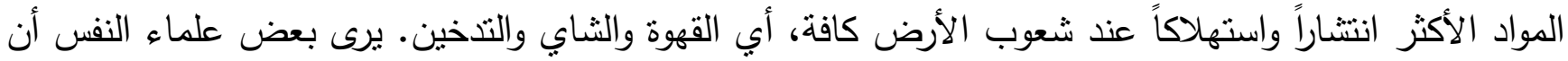
الهذف الكامن وراء الاستهلاك الكبير في الوقت الراهن لهذه المواد هو إعادة تكييف الجسد الإنساني مع طبيعة

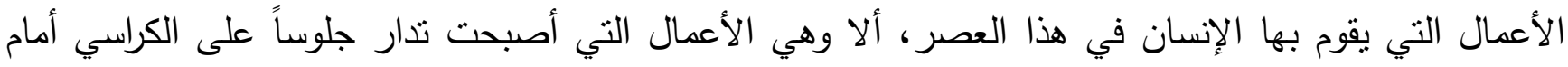
الآلات أو أجهزة الكمبيوتز في أغلبها. فقد أصبح الدماغ الجزء الأكثر أهمية من باقي أعضاء الجسد الإنس في يومنا هذا.

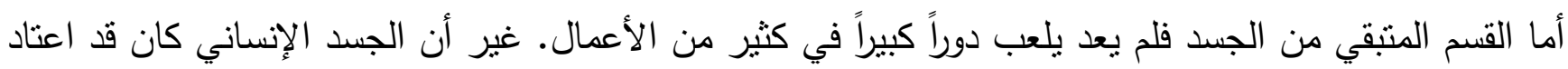

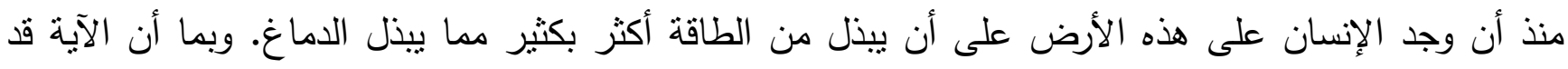
انعكست بشكل كبير في الوقت الراهن، فإن الجسد والدماغ يحتاجان لهذه المواد "المساعدة" من أجل تحقيق نوع من الإنس التوازن يقوم على تتشيط الدماغ من أجل أداء وظائفه بصورة أفضل، وفي الوقت نفسه التخفيض من نشاط باقي أقسام الجسد كي تتاح الفرصة للاماغ للقيام بما هو مطلوب منه. فالقهوة أو الثشاي، بما يحتويانه من مادة الكافيين، يؤثران بشكل إيجابي من خلال تتشيط الدماغ، أما النيكوتين فيؤثز سلباً من خلال تهئته (كبحه) لنشاط باقي

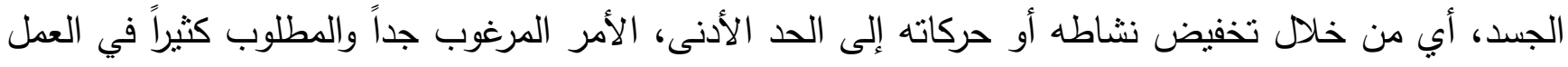

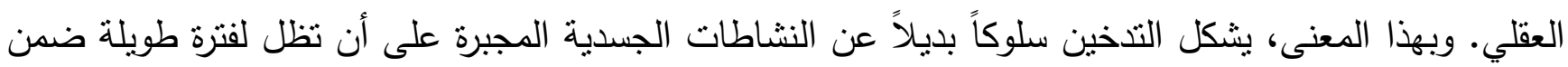
الحد الأدنى من النشاط والحركة ليتاح للدماغ تأدية وظائفه. وهذا هو السر الكامن خلف كثثر من "عقاقير الحياة

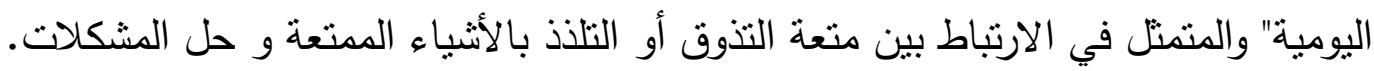

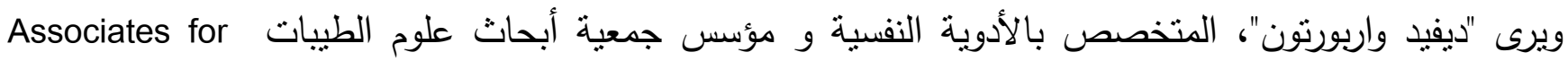
Research into the Science of Enjoy الإنسان، ويجعله عرضة لكثير من الأمراض - حتى الزكام البسيط. وقد توصل "واربورنون" في دراسات أجريت على 5000 موظف في 16 بلداً حول كيفية تغلبهم على الضغط و عاداتهم الاستهلاكية أن الاستهلاك - بمقدار معين لا إفراط فيه - للطيبات كالثوكولاتة والقهوة والثاي و (التنخين!) يمكن أن يقود إلى تقوية المناعة عند الإنسان. أما السبب الرئيسي للضغط النفسي فكان كثرة العمل. وكلما كانت المؤسسة أو الثركة أكبر ، كان الميل

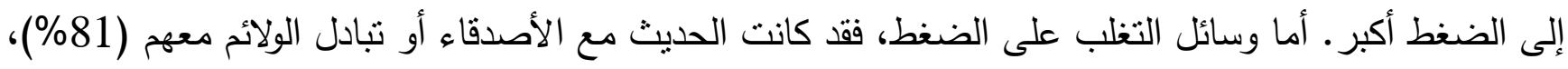
شرب القهوة والثاي (68\%)، والعصير (50\%) وتتاول الحلويات كالثوكولاته وما شابه (27\%) التدخين (27\%). 
وقد رأى 90\% من عينة الدراسة أن هذه المواد فاعلة جداً في التغلب على الضغط، بل وتحسن الكفاءة. وأن غالبية

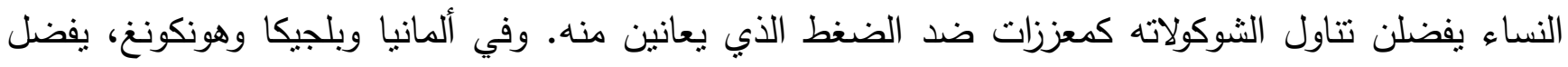

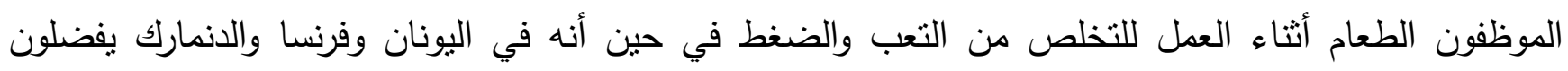

التخخين.

\section{ولكن، كيف يمكن لأطعمة المساعدة في التظلب على الضغط؟}

يرتبط تفضيلنا لنوع معين من الطعام بالجسد. فعندما نشعر بشهية لنوع محدد من الطعام، فإن ذلك يعود بالدرجة

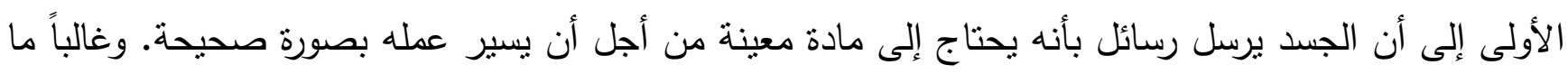

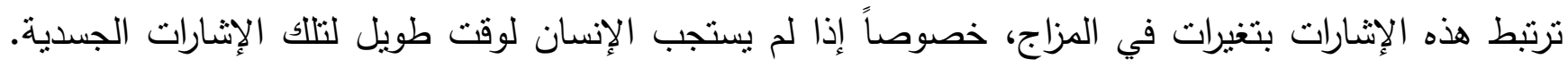

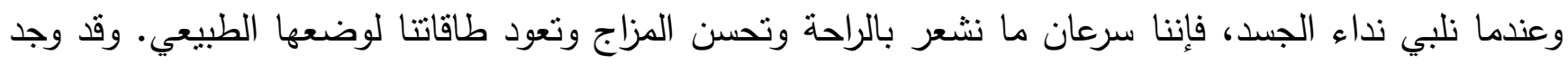

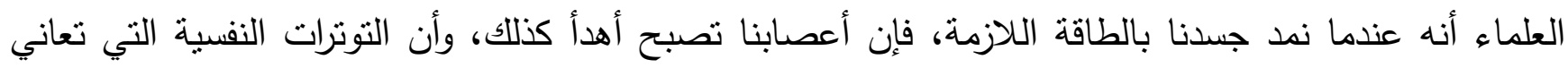

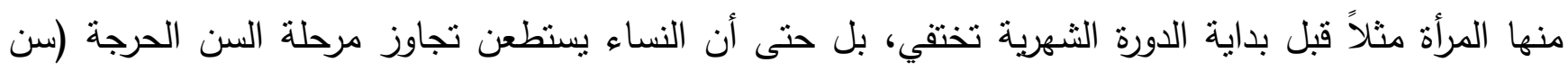

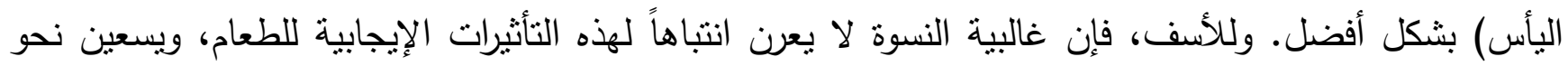

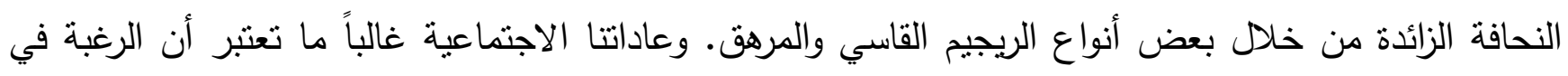

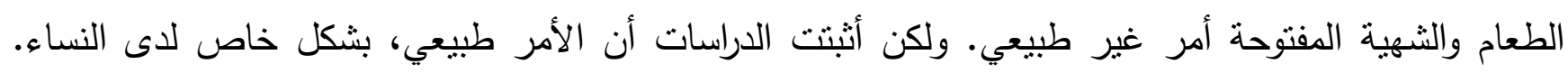

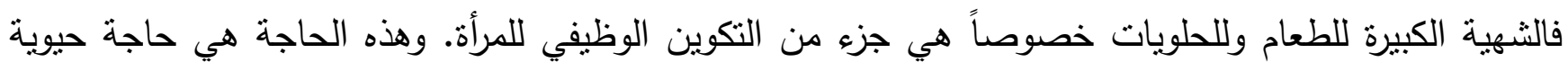

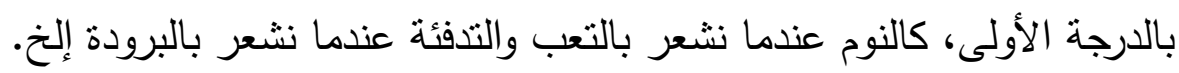

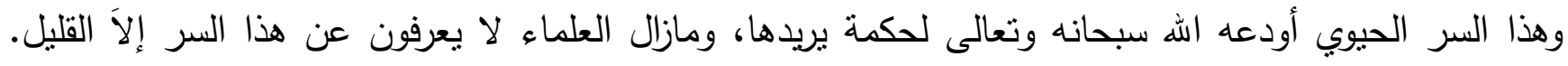

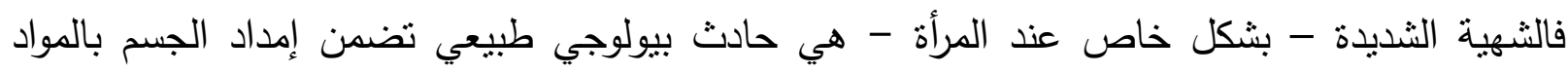
الغذائية الكافية، وتحافظ على الإمداد المناسب للدماغ بالسكر ، و بالتالي على نوازننا النفسي. وهذه الثهية تعكس التهب

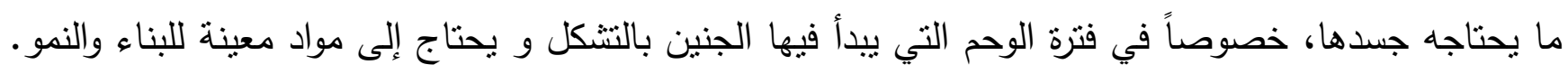

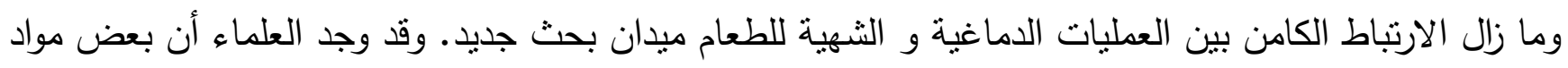

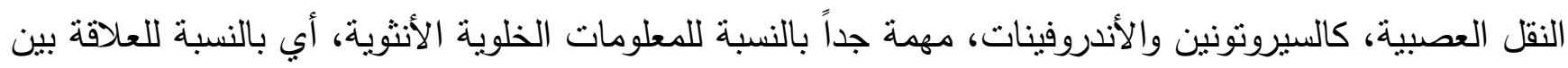

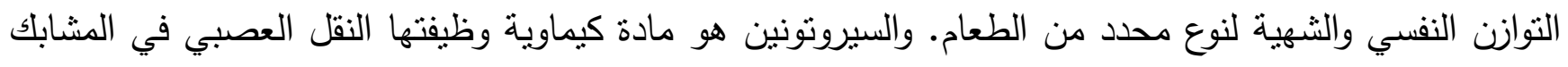

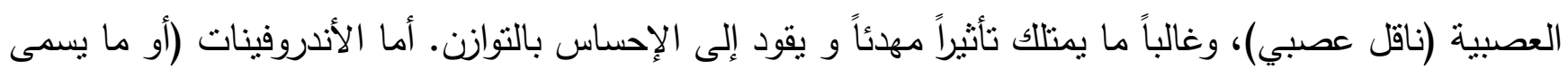

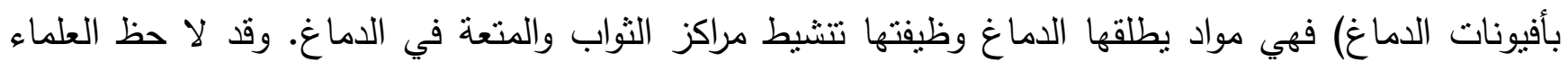
ازدياد إفراز أو تحرير هذه المواد بعد تتاول الدهون والسكريات (بشكل خاص الشوكولاته). فالمواد الدهنية والسكريات تساعد على الإحساس بالراحة الجسدية، أي تمد الجسد بالطاقة اللازمة للعضلات وحث الدماغ إن على إطلاق 
السيروتونين و الأندروفينات التي تجعلنا نشعر بالراحة النفسية والإحساس بالهذوء والرضى، وكل هذه المواد تساعدنا

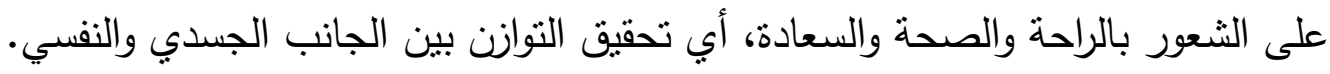

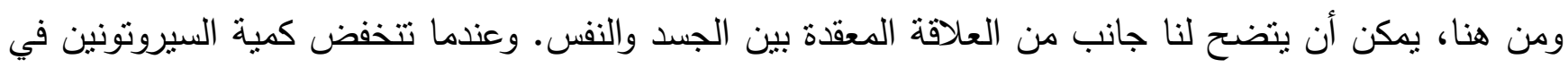
الاماغ، يشعر الإنسان بالإحباط والتوتر الحاجة إلى أكل النشويات (كالخبز والبطاطا أو الرز) أو أو للسكريات (الفاكهة أو العصير ...إلخ) من أجل رفع كمية السيروتونين في الجسد. وعليه، عندما يأكل الإنسان ما يشعر بأنه

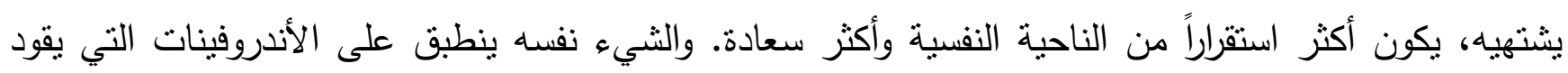
انخفاض محتواها إلى الثعور بالتعب والإنهاك وبالتالي إلى الحاجة الجسدية للاهون والسكريات (الثوكولاته). ويعتقد العلماء أن كمية هذه المواد تتخفض مع بعضها البعض وبالتالي يشعر الإنسان بحاجته للاهون والسكر معاً. فقد وجدوا أن النساء غالباً ما يمتلكن شهية (طبيعية) كبيرة للطعام المركب من الدهون والسكر أكثر من الطعام

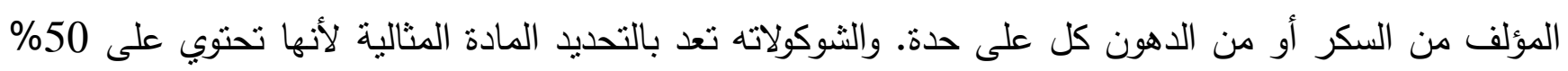

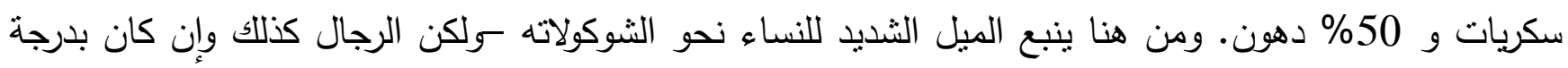

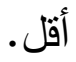
ولكن، لماذا النساء بالتحديد، أكثر من الرجال، هن اللواتي يمتلكن هذا الارتباط الحيوي الثديد بين الحاجة لنوع

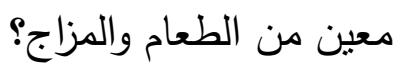

على الرغم من أن الأمر مازال في طور التجارب والدراسة، إلا أنه يعتقد أن الأمر أبعد من مجرد شهية

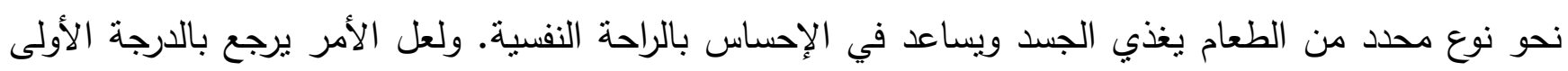

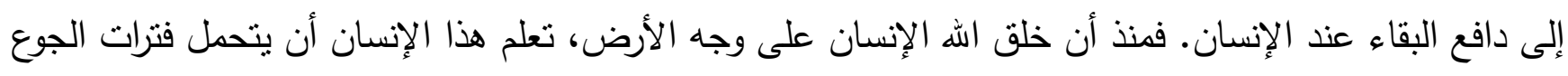

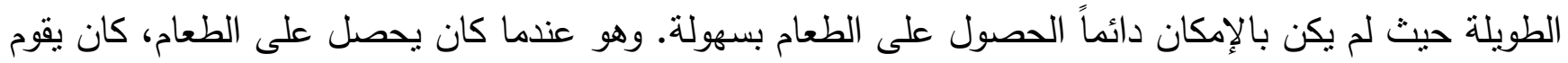

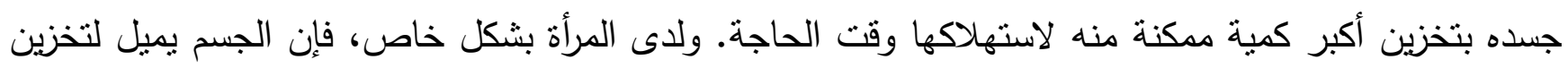

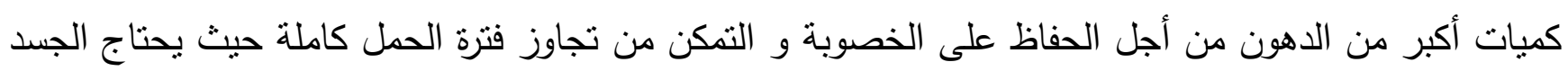

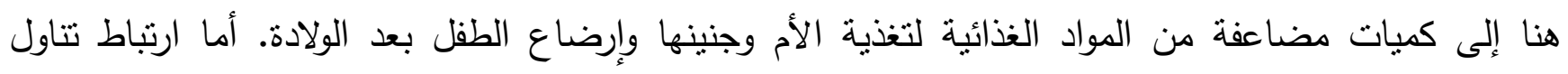

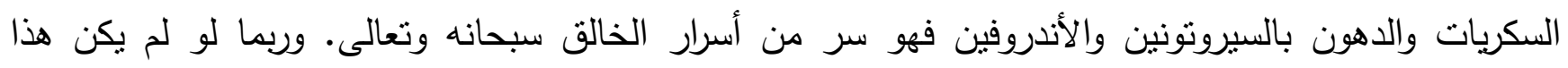

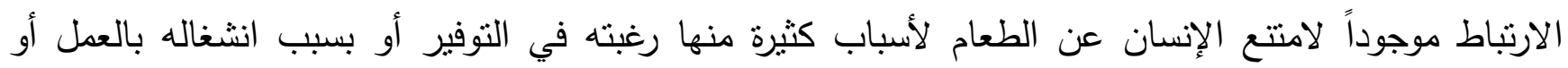

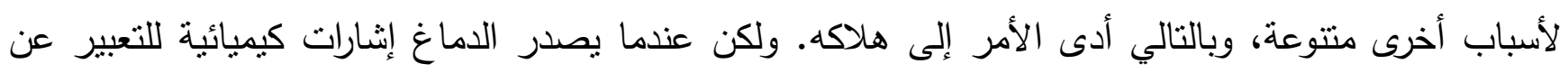

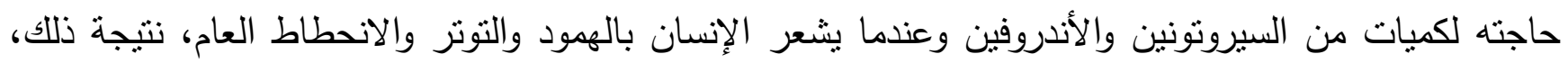

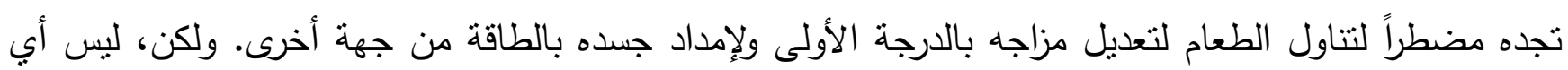
طعام وإنما يشتهي غريزياً ذلك الطعام الذي يمده بما يحتاجه جسده ودماغه دون الحاجة إلى إجراء تحاليل طبية 
عما ينقص جسمه من مواد أو تحليل الأطعمة من أجل البحث فيها عن المادة التي يحتاجها الجسد. ومثل هذا

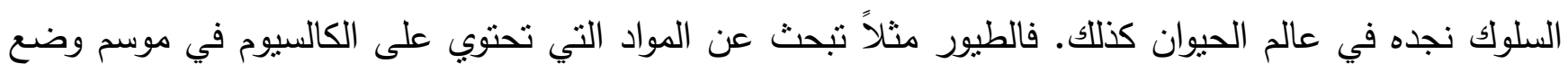

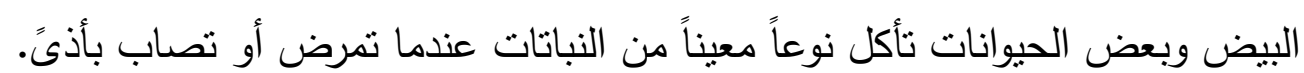

والسؤال المطروح هنا ما علاقة ذلك بالسلوك الإدماني الذي أثشنا إليه آنفاً؟

بما أن النقص في هذه المواد يسبب الثعور بالانزعاج، ويقود إلى إرسال إثنارات معينة من الدماغ تثير

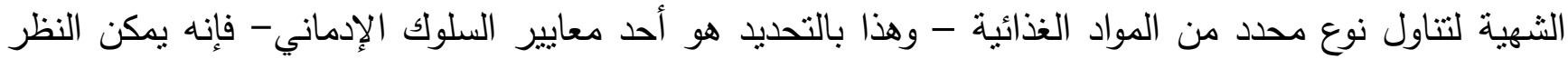

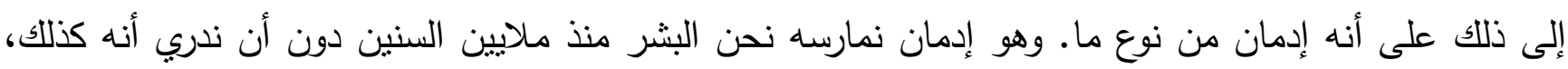

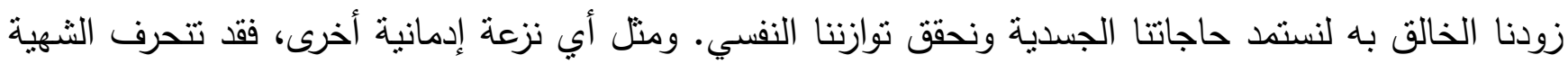

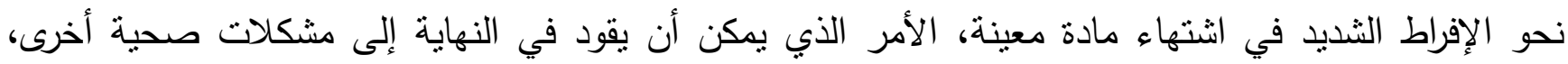
كالوزن الزائد أو السمنة إلخ، وبالتالي إلى عواقب وخيمة يصعب في كثير من الأحيان التتبؤ بنتائجها. 